This item was submitted to Loughborough's Research Repository by the author.

Items in Figshare are protected by copyright, with all rights reserved, unless otherwise indicated.

\title{
Weak signals in healthcare: The case study of the Mid-Staffordshire NHS Foundation Trust
}

PLEASE CITE THE PUBLISHED VERSION

https://doi.org/10.1007/978-3-319-96098-2_84

\section{PUBLISHER}

(C) Springer

VERSION

AM (Accepted Manuscript)

\section{PUBLISHER STATEMENT}

This is a pre-copyedited version of a contribution published in Bagnara, S. ... et al. (eds.) 20th International Ergonomics Association (IEA2018): Volume I: Healthcare Ergonomics published by Springer. The definitive authenticated version is available online via https://doi.org/10.1007/978-3-319-96098-2_84

LICENCE

CC BY-NC-ND 4.0

\section{REPOSITORY RECORD}

Carman, Eva-Maria, Mike Fray, and Patrick Waterson. 2019. "Weak Signals in Healthcare: The Case Study of the Mid-staffordshire NHS Foundation Trust”. figshare. https://hdl.handle.net/2134/35084. 


\title{
Weak Signals in Healthcare: The Case Study of the Mid- Staffordshire NHS Foundation Trust
}

\author{
Eva-Maria Carman ${ }^{\bowtie 1[0000-0002-8509-9788]}{ }^{\text {, Mike Fray }}{ }^{1}$ and Patrick Waterson ${ }^{1}$ \\ ${ }^{1}$ Human Factors and Complex Systems Research Group, Loughborough University, UK \\ E.Burford@lboro.ac.uk, M.J.Fray@Lboro.ac.uk, \\ P.Waterson@Lboro.ac.uk
}

\begin{abstract}
Most organisational disasters have warning signals prior to the event occurring, which are increasingly appearing in accident reports. In the case of the Mid-Staffordshire Disaster, the disaster was not as a result of component failure or human error but rather an organisation that drifted into failure with precursory warning signals being ignored. It has been estimated that between 400 and 1200 patients died as a result of poor care between 2004 and 2009. The aim of this study was to identify the precursory signals and their rationalizations that occurred during this event. Qualitative document analysis was used to analyse the independent and public inquiry reports. Signals were present on numerous system levels. At a person level, there were cases of staff trying to make management aware of the problems, as well as the campaign "Cure the NHS" started by bereaved relatives. At an organisational level, examples of missed signals included the decrease in the trust's star rating due to failure to meet targets, the NHS care regulator voicing concern regarding the unusually high death rates and auditors' reports highlighting concerns regarding risk management. At an external level, examples included negative peer reviews from various external organizations.
\end{abstract}

Keywords: Healthcare Safety, Systems Approach, Weak Signals (need 3)

\section{Introduction}

An organisational disaster can be defined as a low-probability, high impact event with the potential to threaten an organisation's survival [1]. Most organisational disasters have warning signals prior to the event occurring [2], which are increasingly appearing and receiving progressively more attention in accident reports. These warning signals are sensed information regarding emerging events [3], and include indicators or cues from the environment [4] which require interpretation and sensemaking [5]. Many of these warning signals are often also referred to as weak signals, as the information they contain is frequently imprecise and vague in nature [3].

These signals are gaining increasing interest in the research community as they may provide an opportunity to achieve pro-activeness and promote effective risk management, as they provide an opportunity "sooner-rather-than-later" for identifying 
problems that threaten safety [6]. Furthermore, by using signals, unexpected events may be addressed in a more cost-effective and timely manner [7]. In healthcare, this could result in significant benefits particularly with regards to patient health. Furthermore signals may provide an opportunity to render a system more resilient [8] as they provide insight regarding the status of the system and areas of risk [9]. By identifying where these signals originate from and understanding how signals are identified and interpreted, possible changes to work structure and management could be developed to encourage signal identification for promoting patient safety. Despite their potential for improving safety, research exploring signals, especially in healthcare, is limited.

\subsection{Case Study Description}

This case study focused on the failings surrounding the Mid-Staffordshire NHS Foundation Trust, which resulted in unacceptable standards of care for patients between the years of 2004 and 2009 [10]. During this time, there was a noted rise in patient mortality and complaints relating to clinical care, with an estimate of between 400 and 1200 excess deaths occurring during this time period [10]. As a result of the substandard care, many patients were left struggling to care for themselves [11]. The investigation into this organisational disaster found that the system failed to protect patients from unacceptable risk, and in several cases inhumane treatment [12]. The systemic failings were so pronounced, that this event has been described as:

"the worst crisis any district general hospital in the NHS can ever have known" [12, p. 47].

Events contributing to the failings that resulted in unacceptable standards of care to occur at this Trust have been dated back to about 2001 [13]. Initial concerns regarding the Trust were report in August of 2001 and January 2002 to the NHS Executive West Midlands. These were related to staffing levels, leadership and management problems [13]. Over the period from 2004 to 2009, several key events or changes occurred within the organisation, that could be seen as contributing towards the downward spiral the Trust experienced. Some of these included the suspension of reporting patient complaints to the hospital trust board from 2003 to 2006 [14], a financial recovery plan that was put in place in 2005, the modification of the ward structure to include two new units and reconfiguration of the clinical floors and at the end of 2005 the replacement of the Chief Executive [13]. Additionally the director of Nursing was replaced at the end of 2006, the Trust request $£ 1$ million for redundancies twice in 2006, and the Trust (the Mid-Staffordshire General Hospital NHS Trust) received foundation trust status beginning of 2008 [12]. Over this period, numerous reviews, audits and reports were conducted, of which many suggested concerns regarding staffing, managerial and other concerns.

In 2008, the Health Care Commission (HCC) were approached based on above average mortality rates to investigate the Trust. The investigation found that the staffing shortages, operational problems and a lack of leadership meant that despite the best efforts of staff, the quality of care was compromised and patient safety was at risk [13]. In response to the HCC investigation, the above-average mortality rates and the 
persistent complaints made by a group of patients, named "Cure the NHS", an independent inquiry was launched [13].

The independent inquiry, which concluded in 2010 [11] and resulted in the publication of what has become known as the Francis Report, recounted detailed accounts of inadequate care and incidents that identified unexpected risks that patients experienced. These included malnutrition and dehydration [15]. Due to the extensive public outcry, the independent inquiry was followed by a public inquiry which concluded in 2013 [12].

Numerous system factors were identified as contributing to the appalling standards of care patients received [12]. Examples of these included inadequate staffing, negative culture, professional disengagement regarding reporting concerns, poor governance, a lack of focus on standards of service, inadequate risk assessments, and incorrect priorities [16].

The above description of the events surrounding the Mid-Staffordshire NHS Foundation Trust is a brief summary and not an exhaustive description of the events and occurrences. The purpose of this summary is to provide the context for the results included below. Additional events will be mentioned in the results as they directly relate to signals.

\section{Method and Analysis Frameworks}

Signals and their relation to organizational disasters are gaining increasing interest and traction among the research community. Signals are increasingly mention in accident reports, with the an entire section of the Public Inquiry report [13] of the Mid-Staffordshire NHS Foundation Trust dedicated to them. The aim of this study was to analyse the signals identified in the 2013 report as well as other signals that could be extracted from the event descriptions included in both reports for this example of a healthcarerelated organisational disaster using a systems approach. The objectives of this case study included determining the possible sources of signals and the rationalizations that affect action and response to these signals.

An explorative qualitative method was adopted to investigate these due to the fuzzy nature of weak signals. The two reports generated by the independent [11] and public [13] inquiries into this Mid-Staffordshire Disaster were selected for analysis using thematic analysis [17]. The signals and related events leading up to the May 2009 were included in the analysis.

The two models selected for the analysis were the SEIPS 2.0 model [18] and the Weak Signals Framework [19]. The SEIPS 2.0 model was selected as it a systems model that has not only been used to understand healthcare processes better to improve patient safety [20], [21] but also to understand infection outbreaks within acute care settings to identify the larger system contributing factors of the outbreaks [22]. The Weak Signals Framework was selected for the analysis as it provides a structure for the analysis of weak signals in the context of the work, actions and events in the system in which they occur specific for the healthcare context. The framework provided a point of reference for the analysis of related and key information relating to signals. By 
analysing the signals from this perspective, one identifies the sources and the related rationalizations. This together provides a greater understanding on the context in which these signals occur. The Weak Signals Framework is depicted in Figure 1.

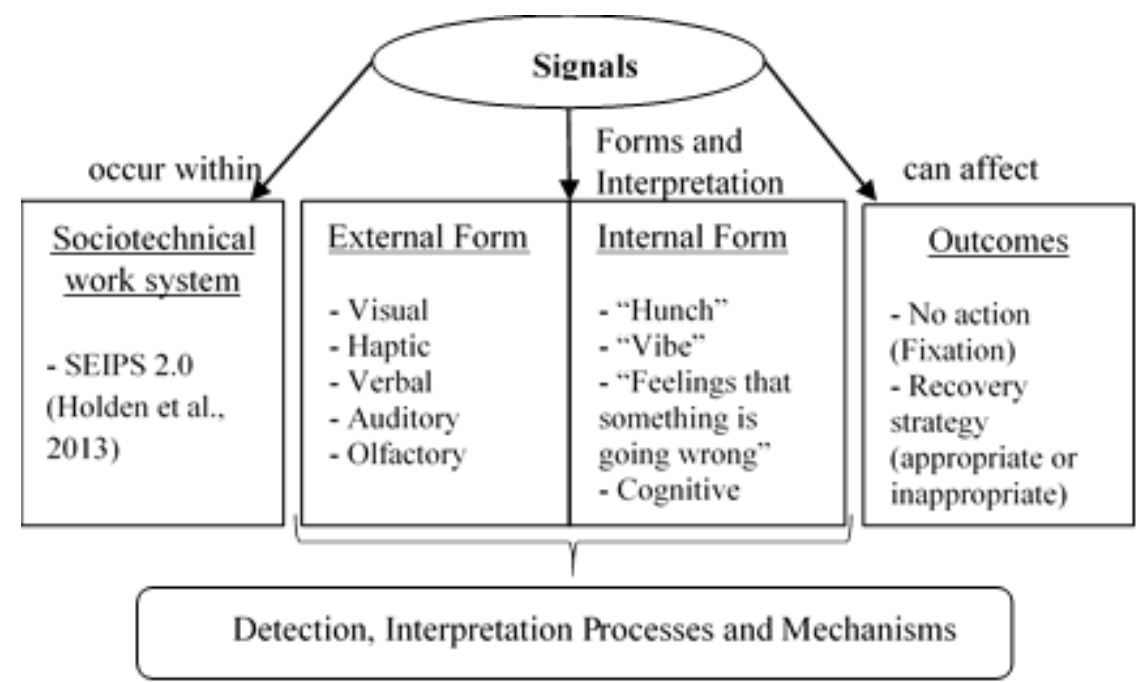

Fig. 1. The Weak Signal Framework for the investigation of weak signals within the healthcare context.

Signals were identified and grouped according to the elements in the sociotechnical work system, as described in the SEIPS 2.0 model, from which they originated, the types, and the associated rationalizations. All data were analysed using NVivo 10 (QSR International, 2014) using thematic analysis [17].

\section{Results}

From the analysis, an extensive list of signals, categorised according to the system levels from which they originated was created. In addition to the examples of signals collected, corresponding rationalizations were included where available for the signals.

Numerous signals, some stronger than others, were extracted from the official reports. A collection of examples from the different system levels, the year they were presented and the rationalizations for why no action was taken is included in Table 1. As is clear from the table, numerous signals were present over the time period, though many were rationalized away. From the analysis, it is clear that many different factors contributed to this disaster and numerous signals were present, but for brevity, only a few key examples are included here. The majority of the signals were identified from 
the person, organization and external environment levels of the Work System Element of the SEIPS 2.0 model.

Table 1. A selection of signals, the year they occurred, and their corresponding rationalizations identified in the two reports.

\begin{tabular}{|c|c|c|c|}
\hline $\begin{array}{l}\text { System } \\
\text { Component }\end{array}$ & Signal & $\begin{array}{l}\text { Examples } \\
\text { (Year of occurrence) }\end{array}$ & Rationalization \\
\hline Person & $\begin{array}{l}\text { Patient } \\
\text { Complaints } \\
\text { Staff behaviour } \\
\text { and complaints } \\
\text { Whistleblow- } \\
\text { ing } \\
\text { Management } \\
\text { voiced } \\
\text { concerns }\end{array}$ & $\begin{array}{l}\text { Patients reported inappropriate } \\
\text { attitudes of staff (2002). } \\
\text { Staff voiced concerns regarding } \\
\text { reconfiguration of wards (2005). } \\
\text { Whistleblowing regarding con- } \\
\text { duct of senior staff (2005, 2007). } \\
\text { The medical director voiced } \\
\text { concerns about the surgical de- } \\
\text { partment (2007) }\end{array}$ & $\begin{array}{l}\text { Patient's feared repercus- } \\
\text { sions. } \\
\text { Staff were told their input } \\
\text { had been considered. } \\
\text { She was advised to "keep } \\
\text { her head down". }\end{array}$ \\
\hline \multirow[t]{3}{*}{ Organization } & $\begin{array}{l}\text { Loss of star } \\
\text { ratings }\end{array}$ & $\begin{array}{l}\text { Loss of star rating due to } \\
\text { breaches in waiting times and } \\
\text { financial deficit (2004). }\end{array}$ & $\begin{array}{l}\text { The tool was criticized } \\
\text { for being a blunt assess- } \\
\text { ment tool. }\end{array}$ \\
\hline & $\begin{array}{l}\text { Financial } \\
\text { recovery plan }\end{array}$ & $\begin{array}{l}\text { Despite staffing levels con- } \\
\text { cerns, a plan containing redun- } \\
\text { dancy was implemented (2005). }\end{array}$ & $\begin{array}{l}\text { Staff reductions seemed } \\
\text { to be consistent with pro- } \\
\text { posed reduction in beds. }\end{array}$ \\
\hline & $\begin{array}{l}\text { Negative } \\
\text { Statistics }\end{array}$ & $\begin{array}{l}\text { Mortality statistics were above } \\
\text { average. }\end{array}$ & $\begin{array}{l}\text { There were concerns with } \\
\text { the coding. }\end{array}$ \\
\hline $\begin{array}{l}\text { Internal } \\
\text { Environment }\end{array}$ & Outbreaks & $\begin{array}{l}\text { Outbreaks of Clostridium dif- } \\
\text { ficile }(2008,2009)\end{array}$ & $\begin{array}{l}\text { It was claimed an action } \\
\text { plan was underway. }\end{array}$ \\
\hline \multirow[t]{3}{*}{$\begin{array}{l}\text { External } \\
\text { Environment }\end{array}$} & $\begin{array}{l}\text { Findings in } \\
\text { Reviews, } \\
\text { Audits and } \\
\text { Surveys }\end{array}$ & $\begin{array}{l}\text { Reviews included Children’s } \\
\text { Service Review (2003, 2004, } \\
\text { 2006, 2008), National Review of } \\
\text { Medicines Management (2006), } \\
\text { National Cancer Review (2005, } \\
\text { 2006), Royal College of Sur- } \\
\text { geons Review (2007) }\end{array}$ & $\begin{array}{l}\text { Rationalizations included } \\
\text { it was thought action was } \\
\text { being taken prior to the } \\
\text { reports being published, } \\
\text { the complaints were lim- } \\
\text { ited to one ward and not }\end{array}$ \\
\hline & $\begin{array}{l}\text { Findings in } \\
\text { Official } \\
\text { Reports }\end{array}$ & $\begin{array}{l}\text { Reports included Commission } \\
\text { of Health Improvement Report } \\
\text { (2002), Barry Report (2005), Dr } \\
\text { Foster Report (2007) }\end{array}$ & $\begin{array}{l}\text { reflective of wider con- } \\
\text { cerns, and not all data } \\
\text { had been submitted for } \\
\text { consideration. }\end{array}$ \\
\hline & $\begin{array}{l}\text { HCC } \\
\text { Investigations }\end{array}$ & $\begin{array}{l}\text { HCC investigation highlighted } \\
\text { concerns regarding basic nurs- } \\
\text { ing care and medication (2008) }\end{array}$ & $\begin{array}{l}\text { Other regulation bodies } \\
\text { decided to await the out- } \\
\text { come of the investigation }\end{array}$ \\
\hline
\end{tabular}

Person level signals identified included patient complaints, staff complaints and behaviours, whistleblowing by staff and management staff voicing concerns. Highlighted in both the first and second inquiry reports, was that senior management was not made 
aware of the concerns of patients and frontline staff [12]. This is highlighted by the following extract:

$$
\begin{aligned}
& \text { "Incidences of poor care were not formally fed through the system and } \\
& \text { they were not supplied to commissioners or regulators... "[13, p. 47] }
\end{aligned}
$$

However, staff did speak up which was visible in several different types of signals. Examples of these include the person level signals relating to staff whistleblowing on senior staff's conduct and staff voicing their complaints regarding the reconfiguration of certain wards. Furthermore, based on the Barry Report, published in 2005, which was a report generated as a result of a whistle blowing complaint, staff were trying make management aware of the current situation, which contradicts the above statement [13, p. 69]. With regards to staff voicing concerns regarding the reconfiguration of wards, this signal was met with the rationalization that the staff had already given input. Another example of a signal related to the concerns of staff, which was identified though an internal staff survey conducted in 2007 , which could be seen as an organization level signal, is highlighted by the following extract:

$$
\begin{aligned}
& \text { "Concern was expressed at the percentage of staff who said they } \\
& \text { would not want to be treated at the hospital, nor wish a relative to be either." [13, p. 98] }
\end{aligned}
$$

An example of a signal that was identified where management staff voiced concern was that the medical director reported concerns about the surgical department. Elements of the strength of the signal and the response to signal is indicated in the extract below:

\footnotetext{
"From the time of her appointment as Medical Director, ... had harboured concerns about the Surgical Department. ... She had a number of audits and other reviews undertaken but these came up with no evidence of concern. She approached the National Clinical Assessment Service (NCAS) who agreed with her proposal to invite the Royal College of Surgeons (RCS) to conduct a review...” [13, p. 111]
}

This is a prime example of a weak signal, as the staff member was convinced that there was a problem despite evidence contradicting this. With hindsight, it has been confirmed that there were reasons for concern.

Organization level signals identified included the loss of the Trust's star rating; implementation of a financial recovery plan that included redundancies despite staffing level concerns; and negative organizational statistics such as above average mortality statistics. The loss of stars signal was rationalized away in questioning the validity of the assessment tool. The rationalization for the financial recovery plan was that the proposed staff reductions were in-line with the proposed reduction in beds. The signal of the above average mortality rates appears to be one of the strongest signals in this case study. Despite the rationalization of the metric being subject to concerns, especially regarding the coding of the data, this signal, possibly in addition to several weaker ones, initiated the greatest response, namely the HCC investigation and the first inquiry. This signal was identified by several sources, and can be considered as an organization 
level signal. However, this signal also featured in the external environment signal "Dr Foster report”. The strength of the signal is highlighted by the extract below:

"... it has to be concluded that this was a clear alarm bell requiring urgent action to find out whether this result could be explained by a review of the care provided.” [13, p. 100]

Internal environment level signals identified included two outbreaks of Clostridium difficile, one in 2008 and 2009. These signals directly reflect the concerns relating to the key areas identified by the independent inquiry of continence, bladder and bowel care; safety; personal and oral hygiene; and cleanliness and infection control [11]. Furthermore, following the outbreak in 2008, senior staff raised concerns, which should have been a signal to management, as they felt unhappy about the Trust's reaction to outbreak as there had been an insufficient sense of urgency.

External environment level signals identified included the findings of external and peer reviews, audits and surveys; findings from official reports and the HCC investigation. Several reviews, investigations, audits and surveys were repeated over the time period in question whereby on numerous occasions similar results were found. Numerous concerns highlighted in the report published in 2010 were concerns that had been mentioned in earlier reports, for example the Barry Report in 2005 highlighted inadequate handovers, deficient note keeping, poor standards of care, inappropriate management style and inappropriate behaviour by staff [13, p. 64].

The HCC investigation was an unusual event and should have been considered as a signal to other regulatory bodies that there was a need for concern regarding this Trust's performance. Other oversight and regulation bodies decided to await the outcome of the investigation, which is a form of rationalization.

\section{$4 \quad$ Discussion and Recommendations}

The events surrounding the Mid-Staffordshire NHS Foundation Trust can be qualified as an organizational disaster by the definition provided in the introduction [1], as in its entirety it was a high impact event that threatened the survival of the organization, in this case this specific Trust. As a result of this organizational failure, numerous patients lost their lives, experienced unacceptable standards of care and undignified treatment, and in addition to this, the inquiries into this event have cost approximately $£ 19$ million and ultimately have led to the trust being dissolved in 2014 and services being relocated to other centres.

In this case study, the drift into failure through ignoring precursory signals is quite evident. This is visible in that as system components and safety processes were failing, the signals indicating this were rationalised away or the response was too weak to prevent the failures from still occurring. This is visible from the results above, specifically with regards to the numerous signals available over the time period as well as the repetition of various signals.

Through the analysis of signals and their rationalizations in this case study, insights into the characteristics of signals can be extracted. The characteristics included the 
repetition of signals and the accumulative effect of signals. One would expect the extent and severity of what was occurring, to have been derivable from some individual signals if they were clear and strong enough, for example the higher system level signals such as Commission of Health Improvement Report in 2002 or the loss of the star rating in 2004. But also, a combination of slightly weaker signals, repetition or the accumulation of these signals should have notified management of what was occurring. Examples of repeated signals included the outbreak of Clostridium difficile and external peer reviews.

Furthermore the clarity of the information regarding what was occurring at this Trust should have become more apparent with the repetition or accumulation of signals [23]. The findings in official investigations and reports, which provide evidence-based information, and as a result may be considered as relatively strong higher system level signals, can be seen as an accumulation of signals. The reports usually comprised of an accumulation of lower system level signals, including person level signals, for example patient complaints and staff behaviours, task level signals and internal environment level signals. But in this case study, the majority of the signals, both lower and higher system level signals, were rationalized away, and then occurred later in the timeline again.

A common theme among the rationalizations was that the Trust assured external and regulatory bodies that progress had been made in correcting perceived deficiencies at numerous different time points. And there appeared to have been a lack of follow up on the previously generated reports. Additional system factors that prevented signals from being noticed and responded to include a negative culture, professional disengagement regarding reporting concerns, poor governance, a lack of focus on standards of service, inadequate risk assessment of staff reduction, and incorrect priorities[12].

The case study also highlights how rationalizations from one signal may impact the "face-value" of other signals. An example of this was that it was felt that if the severe staff cutting to meet the needs of the cost improvement plan had negative effects, this would have been highlighted in other performance measures. But unfortunately, the Trust's performance measures had been highlighted as unreliable and the systems for collecting and coding for these measures were seen as inadequate.

\section{Conclusion}

Signals provide an opportunity for insight regarding the status of the system and areas of risk [9]. But unfortunately, these signals are often rationalized away. As with many organisational disasters, this one too highlights the difficulty of recognising and accurately acting upon signals of imminent failure [2]. This case study highlighted examples of numerous different system level signals and their associated rationalizations. The source of the signals was a focus of this case study as incorporating signals in risk management requires being able to identify where these signals originate, namely "knowing where to look for them". The second key focus of this case study was that of 
the rationalizations of signals. One needs to know the rationalizations for signals to better understand the factors that hinder acting upon them when identified.

It is the hope of this research that by understanding why signals were dismissed previously and the responses taken in the past, a better action plan may be developed for the current unfolding situation. One needs experience or cases to create precedents, which one needs to assist in creating operational policy. This case study is an example of how healthcare can suffer from an organizational failure. It is essential that one learns as much as possible to inform policy and procedure so that safe guards for this kind of failure can be developed and put in place.

\section{References}

[1] W. J. Duncan, V. A. Yeager, A. C. Rucks, and P. M. Ginter, "Surviving organizational disasters,” Bus. Horiz., vol. 54, no. 2, pp. 135-142, Mar. 2011.

[2] C. Wei Choo, "Organizational disasters: why they happen and how they may be prevented," Manag. Decis., vol. 46, no. 1, pp. 32-45, Feb. 2008.

[3] I. Ansoff and E. Mcdonnell, Implanting strategic management, Second Edi. United Kingdom: Prentice Hall International, 1990.

[4] J. Rasmussen, "Skills, rules, and knowledge; signals, signs, and symbols, and other distinctions in human performance models," IEEE Trans. Syst. Man. Cybern., vol. SMC-13, no. 3, pp. 257-266, 1983.

[5] K. E. Weick, Sensemaking in Organizations. London: SAGE Publications, 1995.

[6] C. Macrae, Close Calls. Basingstoke: Palgrave Macmillan, 2014.

[7] T. J. Vogus and K. M. Sutcliffe, "Organizational resilience: Towards a theory and research agenda," Conf. Proc. - IEEE Int. Conf. Syst. Man Cybern., pp. 3418-3422, 2007.

[8] E. Hollnagel, Safety-I and Safety-II: The Past and Future of Safety Management. Farnham: Ashgate Publishing Ltd., 2014.

[9] C. Macrae, "Early warnings, weak signals and learning from healthcare disasters.,” BMJ Qual. Saf., vol. 23, no. 6, pp. 440-5, Jun. 2014.

[10] D. J. Roberts, "The Francis report on the Mid-Staffordshire NHS Foundation Trust: putting patients first," Transfus. Med., vol. 23, no. 2, pp. 73-76, Apr. 2013.

[11] The Mid Staffordshire NHS Foundation Trust Inquiry, "Independent Inquiry into care provided by Mid Staffordshire NHS Foundation Trust January 2005 - March 2009, Volume 1,” The Stationary Office Limited, London, 2010.

[12] The Mid Staffordshire NHS Foundation Trust Public Inquiry, "Report of the Mid Staffordshire NHS Foundation Trust Public Inquiry: Executive summary.” The Stationary Office Limited, London, 2013.

[13] The Mid Staffordshire NHS Foundation Trust Public Inquiry, "Report of the Mid Staffordshire NHS Foundation Trust Public Inquiry,” The Stationery Office Limited, London, 2013.

[14] D. Colin Thomé, Mid Staffordshire NHS Foundation Trust: A Review of Lessons Learnt for Commissioners and Performance Managers Following the Healthcare Commission Investigation. 2009. 
[15] C. Vincent and R. Amalberti, Safer Healthcare: Strategies for the Real World. New York: Springer International Publishing, 2016.

[16] The Mid Staffordshire NHS Foundation Trust Inquiry, "Independent Inquiry into care provided by Mid Staffordshire NHS Foundation Trust January 2005 - March 2009 Volume II,” The Stationary Office Limited, London, 2010.

[17] V. Braun and V. Clarke, "Using thematic analysis in psychology," Qual. Res. Psychol., vol. 3, no. 2, pp. 77-101, Jan. 2006.

[18] R. J. Holden, P. Carayon, A. P. Gurses, P. Hoonakker, A. S. Hundt, A. A. Ozok, and A. J. Rivera-Rodriguez, "SEIPS 2.0: a human factors framework for studying and improving the work of healthcare professionals and patients.," Ergonomics, vol. 56, no. 11, pp. 1669-86, Jan. 2013.

[19] E.-M. Carman, M. Fray, and P. Waterson, "Development of a framework for the analysis of weak signals within a healthcare environment," in Organizing for High Performance: Proceedings of the 48th Annual Conference of the Association of Canadian Ergonomists \& 12th International Symposium on Human Factors in Organizational Design and Management, 2017, pp. 265271.

[20] A. J. Rivera, B.-T. Karsh, J. W. Beasley, and et al., "Human factors and systems engineering approach to patient safety for radiotherapy.," Int. J. Radiat. Oncol. Biol. Phys., vol. 71, no. 1 Suppl, pp. S174-7, 2008.

[21] A. P. Gurses, G. Kim, E. A. Martinez, J. Marsteller, L. Bauer, L. H. Lubomski, P. J. Pronovost, and D. Thompson, "Identifying and categorising patient safety hazards in cardiovascular operating rooms using an interdisciplinary approach: a multisite study,” BMJ Qual. Saf., vol. 21, no. 10, pp. 810-818, Oct. 2012.

[22] P. Waterson, "A systems ergonomics analysis of the Maidstone and Tunbridge Wells infection outbreaks.,” Ergonomics, vol. 52, no. 10, pp. 1196-205, Oct. 2009.

[23] E. Hiltunen, "Weak signals in organizational futures learning,” Helsinki School of Economics Acta Universitatis Oeconomicae Helsingiensis, 2010. 